\title{
Erratum to: Taxol from Corylus avellana: paving the way for a new source of this anti-cancer drug
}

\author{
Ana Gallego ${ }^{1}$ - Sonia Malik ${ }^{2} \cdot$ Morteza Yousefzadi $^{3} \cdot$ Abdullah Makhzoum $^{4}$. \\ Jocelyne Tremouillaux-Guiller ${ }^{5} \cdot$ Mercedes Bonfill $^{6}$
}

Published online: 10 February 2017

(C) Springer Science+Business Media Dordrecht 2017

\section{Erratum to: Plant Cell Tiss Organ Cult DOI 10.1007/s11240-016-1164-5}

In the original article, in the second sentence of the Introduction, the increase in cancer-related death was incorrectly specified as 'about $21.1 \%$ per year'. It should be 'about $2.1 \%$ per year'.

The online version of the original article can be found under doi:10.1007/s11240-016-1164-5.

Sonia Malik

777soniamalik@gmail.com

$\triangle$ Mercedes Bonfill

mbonfill@ub.edu

1 Departament de Ciències Experimentals i de la Salut, Universitat Pompeu Fabra, Barcelona, Spain

2 Health Sciences Graduate Program, Biological and Health Sciences Center, Federal University of Maranhão, São Luís, MA, Brazil

3 Department of Marine Biology, Faculty of Marine Science and Technology, University of Hormozgan, Bandar Abbas, Iran

4 Department of Biology, The University of Western Ontario, London, Canada

5 Faculté de Sciences Pharmaceutiques, Université François Rabelais, Tours, France

6 Laboratori de Fisiologia Vegetal, Facultat de Farmacia, Universitat de Barcelona, Barcelona, Spain 